\title{
CONSUMO, DIGESTIBILIDADE APARENTE E BALANÇO DE NITROGÊNIO EM OVELHAS ALIMENTADAS COM DIFERENTES NÍVEIS DE FIBRA EM DETERGENTE NEUTRO
}

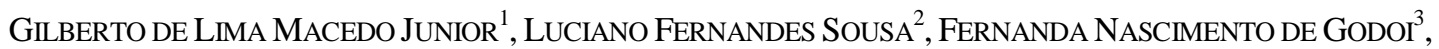

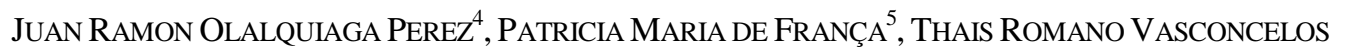 \\ ALMEIDA $^{6}$, OITI JOSÉ DE PAULA ${ }^{7}$, ROBERTA DE MOURA ASSIS ${ }^{8}$ \\ ${ }^{1}$ Professor Doutor, Universidade Federal de Uberlândia, Uberlândia, MG, Brasil - gilbertomacedojr@gmail.com \\ ${ }^{2}$ Professor adjunto Colaborador da Fundação Universidade Federal do Tocantins, Araguaína, TO, Brasil \\ ${ }^{3}$ Doutoranda da Universidade Federal de Minas Gerais, Belo Horizonte, MG, Brasil \\ ${ }^{4}$ Professor Titular da Universidade Federal de Lavras, Lavras, MG, Brasil \\ ${ }^{5}$ Bolsista FAPESP, Programa de Pós-Doutorado da Faculdade de Ciências Agrárias e Veterinárias da Universidade Estadual Paulista, \\ Jaboticabal, SP, Brasil. \\ ${ }^{6}$ Professor de Ensino Básico,Técnico e Tecnológ do Instituto Federal Fluminense, Bom jesus do Itabapoana, RJ, Brasil. \\ ${ }^{7}$ Doutor, Coordenador técnico Núcleo de Inseminação Artificial e Transferência de Embriões, NIARTE, Três Corações, MG, Brasil. \\ ${ }^{8}$ Professora da Universidade Federal de Goiás, Campus Jataí, Jataí, GO, Brasil
}

\begin{abstract}
Avaliou-se a influência de diferentes níveis de fibra em detergente neutro de origem forrageira (FDNf) na dieta de ovelhas sobre o consumo, digestibilidade aparente e balanço de nitrogênio. Foram utilizadas 16 ovelhas adultas, não gestantes e não lactantes, da raça Santa Inês, com peso vivo de 45,01 $\pm 5,15 \mathrm{~kg}$, distribuídas em delineamento quadrado latino $(4 \mathrm{x} 4)$, com quatro tratamentos $(8,67 \%$; $17,34 \%$; $26,01 \%$ e $34,69 \%$ de FDNf), 4 animais e 4 períodos, perfazendo 4 quadrados latinos. As variáveis referentes ao consumo de matéria seca (MS), matéria orgânica (MO), energia bruta (EB), energia digestível (ED), energia metabolizável $(\mathrm{EM})$, proteína bruta $(\mathrm{PB})$, proteína digestível
\end{abstract}

(PD), fibra em detergente neutro (FND) e fibra em detergente ácido (FDA) bem como os coeficientes de digestibilidade aparente da MS, MO, EB e FDA foram influenciados positivamente pelos níveis crescentes de FDNf dos tratamentos. $\mathrm{O}$ balanço de nitrogênio foi positivo em todos os níveis de FDNf. O trabalho evidenciou que existe um limite fisiológico para a utilização de concentrado na dieta de ovelhas, sendo necessária uma quantidade mínima de FDNf para maior eficiência no aproveitamento dos nutrientes; no entanto, esse limite parece ser inferior ao nível mais baixo de FDNf do presente estudo.

PALAVRAS-CHAVE: metabolismo; nutrição animal; ruminantes.

\section{VOLUNTARY INTAKE, APPARENT DIGESTIBILITY AND NITROGEN BALANCE IN EWES FED DIETS WITH DIFFERENT NEUTRAL DETERGENT FIBER LEVELS}

\section{ABSTRACT}

This research was carried to investigate the effect of different levels of forage neutral detergent fiber (fNDF) in the diet offered to ewe on the intake and apparent digestibility of the diet and on nitrogen balance. Sixteen adult, non-pregnant and non-lactating Santa Ines ewes, weighting $45.01 \pm 5.15 \mathrm{~kg}$, were used. The experimental design used was a $4 \times 4$ latin square, with four treatments $(8.67 \% ; 17.34 \% ; 26.01 \%$ and
$34.69 \%$ of fNDF) four animals and four periods. The intake of dry matter (DM), organic matter (OM), gross energy (GE), digestible energy (DE), metabolizable energy (ME), crude protein (CP), digestible protein (DP), neutral detergent fiber (NDF) and acid detergent fiber (ADF) were influenced positively by the levels of fNDF of the treatments. The apparent digestibility of $\mathrm{DM}, \mathrm{OM}, \mathrm{GE}$ and $\mathrm{ADF}$ were 
influenced by treatments. Nitrogen balances were positive at all levels of forage NDF. This study made it clear that there is a physiological limit to the use of concentrate in diets offered to ewe, being necessary a minimum amount of forage NDF

KEYWORDS: animal nutrition; metabolism; ruminants.

\section{INTRODUÇÃO}

A produção animal está estritamente relacionada com a nutrição, a qual depende basicamente de quatro fatores: exigências nutricionais, composição e digestibilidade dos alimentos e quantidade de nutrientes que o animal ingere (ALLISON, 1985). A ingestão de matéria seca é citada como mais importante e determinante no desempenho animal, pois é o delimitador da ingestão de nutrientes necessários ao atendimento das exigências de mantença e de produção.

A fibra é utilizada para caracterizar os alimentos (VAN SOEST, 1994) e estabelece os limites de inclusão de ingredientes em rações; entretanto, não existe consenso quanto à definição de fibra nem quanto à concentração de fibra dietética capaz de otimizar o consumo de energia pelos ovinos.

A presença da fibra na dieta de ruminantes, em maior ou menor proporção, afeta importantes características dos alimentos, relacionando a digestibilidade e o valor energético com a fermentação ruminal e, provavelmente, controla o consumo (VAN SOEST, 1994).

A digestibilidade da fibra de forragens não é constante para todos os animais, tendo como fontes de variação a estrutura da planta, a composição química, a relação volumoso:concentrado além de condições ambientais como temperaturas do ar elevadas. Apesar do grande interesse em se conhecer o nível ideal de fibra na dieta de ovinos deslanados, poucos estudos têm sido realizados com esse intuito.

MACEDO JUNIOR et al. (2009), trabalhando com ovelhas gestantes, observaram que os limites inferior e superior de fibra em detergente neutro de in the diet to reach the maximum efficiency of nutrients use; however, this limit seems to be inferior at the lowest level of fNDF of the current study.

origem forrageira (FDNf) são 20 e $35 \%$, respectivamente. Este trabalho objetivou avaliar se crescentes níveis de FDNf influenciam no consumo e digestibilidade aparente dos nutrientes, assim como no balanço de nitrogênio em ovelhas da raça Santa Inês em mantença, já que limites dietéticos de FDNf são desconhecidos para essa categoria animal.

\section{MATERIAL E MÉTODOS}

O experimento foi realizado no setor de Ovinocultura e as análises bromatológicas realizadas no Laboratório de Pesquisa Animal do Departamento de Zootecnia da Universidade Federal de Lavras.

Foram utilizadas 16 ovelhas da raça Santa Inês com peso médio e desvio padrão de $45,01 \pm 5,15 \mathrm{~kg}$, em quatro quadrados latinos $4 \times 4$, com quatro animais, quatro tratamentos e quatro períodos por quadrado. Os animais foram alojados em gaiolas metabólicas individuais providas de comedouro, bebedouro e saleiro.

As dietas foram balanceadas segundo o ARC (1980), visando suprir as necessidades nutricionais diárias e permitir $10 \%$ de sobras, sendo constituídas de quatro níveis de FDNf: dieta A - com 8,67\% de FDNf; dieta B - com 17,34\% de FDNf; dieta C - com 26,01\% de FDNf; e dieta D - com 34,69\% de FDNf. A alimentação dos animais foi constituída de feno de capim coast-cross (Cynodon dactylon L. Pers.) picado (42 dias de intervalo de corte), milho grão moído (Zea mays L.), farelo de soja (Glicine max) (46\% PB) e sal mineral comercial (Tabela 1), sendo oferecida em duas refeições diárias (às $8 \mathrm{~h}$ e às $15 \mathrm{~h}$ ); a primeira representava $60 \%$ do total diário ofertado.

Tabela 1. Composição nutricional dos ingredientes das dietas, expressa na base da matéria seca

\begin{tabular}{|c|c|c|c|c|c|c|}
\hline \multirow{2}{*}{ Alimentos } & \multicolumn{6}{|c|}{ Contribuição dos ingredientes } \\
\hline & MS (\%) & $\mathrm{PB}(\%)$ & FDN $(\%)$ & FDA (\%) & $\mathrm{Ca}(\%)$ & $\mathrm{P}(\%)$ \\
\hline Feno de Coast cross & 91,30 & 8,53 & 78,63 & 33,93 & 0,733 & 0,434 \\
\hline Milho grão & 86,77 & 10,56 & 21,58 & 4,03 & 0,063 & 0,311 \\
\hline Farelo de Soja & 88,40 & 45,62 & 20,70 & 10,17 & 0,452 & 0,781 \\
\hline Calcário calcítico & 99,99 & - & - & - & 35,84 & - \\
\hline Sal comum & 99,82 & - & - & - & - & - \\
\hline Suplemento Mineral/Vitamínico ${ }^{1}$ & 94,36 & - & - & - & 23,00 & 9,00 \\
\hline
\end{tabular}

${ }^{1}$ Nutrientes/kg de suplemento: cálcio $=230 \mathrm{~g}$; fósforo $=90 \mathrm{~g}$; enxofre $=15 \mathrm{~g}$; magnésio $=20 \mathrm{~g}$; sódio $=48 \mathrm{~g} ;$ cobalto $=100 \mathrm{mg}$; cobre $=700 \mathrm{mg}$; ferro $=2.000 \mathrm{mg}$; iodo $=80 \mathrm{mg}$; manganês $=1250 \mathrm{mg}$; selênio $=200 \mathrm{mg}$; zinco $=2.700 \mathrm{mg}$; flúor $=900 \mathrm{mg}$; vitamina $\mathrm{A}=200.000 \mathrm{UI}$; vitamina $\mathrm{D} 3=60.000 \mathrm{UI}$; vitamina $\mathrm{E}=60 \mathrm{UI}$. $\mathrm{MS}=$ matéria seca, $\mathrm{PB}=$ proteína bruta, $\mathrm{FDN}=\mathrm{fibra}$ em detergente neutro, $\mathrm{FDA}=$ fibra em detergente ácido, $\mathrm{Ca}=$ cálcio, $\mathrm{P}=$ fósforo. 
$\mathrm{O}$ experimento foi realizado em quatro períodos consecutivos e imediatos com 15 dias de adaptação dos animais às dietas e cinco dias de coletas de amostras. Diariamente amostravam-se o feno e os alimentos concentrados, esses últimos já compondo a pré-mistura concentrada, a fim de se obter a composição bromatológica das dietas experimentais (Tabela 2).

Toda a produção fecal era recolhida, pesada e amostrada em 20\%, todos os dias, antes da alimentação matutina, sendo acondicionadas em sacos plásticos devidamente identificados e mantidas a $-20^{\circ} \mathrm{C}$. A urina excretada por animal, em baldes com $100 \mathrm{~mL}$ de ácido sulfúrico a $2 \mathrm{~N}$ para evitar perdas de nitrogênio, foi mensurada e armazenada, a $-20^{\circ} \mathrm{C}$, em uma alíquota de $10 \%$ do volume total. As sobras foram coletadas, identificadas, pesadas e amostradas individualmente para análises posteriores.

Tabela 2. Composição nutricional e contribuição dos ingredientes sobre as características nutritivas das dietas

\begin{tabular}{|c|c|c|c|c|}
\hline \multirow[b]{3}{*}{ Item } & \multicolumn{4}{|c|}{ Dieta com níveis de FNDf } \\
\hline & $8,67 \%$ & $17,34 \%$ & $26,01 \%$ & $34,69 \%$ \\
\hline & \multicolumn{4}{|c|}{ Composição bromatológica } \\
\hline Matéria Seca $(\%)$ & 83,44 & 83,10 & 82,49 & 83,22 \\
\hline Fibra em Detergente Neutro (\%) & 8,67 & 17,34 & 26,01 & 34,69 \\
\hline Fibra em Detergente Ácido \% & 10,92 & 15,99 & 32,35 & 38,90 \\
\hline Proteína Bruta (\%) & 19,59 & 20,47 & 20,61 & 21,02 \\
\hline Matéria Mineral (\%) & 4,41 & 4,49 & 4,60 & 4,70 \\
\hline Matéria Orgânica (\%) & 95,59 & 95,51 & 95,40 & 95,29 \\
\hline \multirow[t]{2}{*}{ Energia Metabolizável (kcal/kg) } & 2.954 & 2.948 & 2.945 & 2.813 \\
\hline & \multicolumn{4}{|c|}{ Proporção dos ingredientes nas dietas (\%) } \\
\hline Feno de Coast cross & 10,00 & 20,00 & 30,00 & 40,00 \\
\hline Milho & 66,50 & 56,50 & 46,50 & 37,50 \\
\hline Farelo de soja & 22,50 & 22,50 & 22,50 & 22,50 \\
\hline Suplemento Mineral/Vitamínico & 1,0 & 1,0 & 1,0 & 1,0 \\
\hline
\end{tabular}

Nas amostras de fezes, sobras e alimentos foram determinados os seguintes valores: matéria seca (MS), fibra em detergente neutro (FDN), fibra em detergente ácido (FDA), proteína bruta (PB), energia bruta (EB) e matéria mineral (MM). Nas amostras de urina realizaram-se as análises de proteína bruta $(\mathrm{PB})$ e energia bruta $(\mathrm{EB})$. As análises químicas foram efetuadas segundo a metodologia descrita por SILVA e QUEIROZ (2002). Os valores de energia metabolizável (EM) foram obtidos pela diferença entre energia digestível e perdas energéticas, advindas da formação de metano e da urina, seguindo fórmulas propostas por SNIFFEN et al. (1992):

$$
\begin{aligned}
& \mathrm{EM}=\mathrm{EBI}-(\mathrm{EBF}+\mathrm{EBU}+\mathrm{EPGD}) \\
& \mathrm{EPGD}=\mathrm{PGD} \times \mathrm{XBI} / 100 \\
& \mathrm{PGD}=4,28+0,059 \mathrm{CDEB}
\end{aligned}
$$

Os valores dos coeficientes de digestibilidade aparente (CD) dos nutrientes foram obtidos pela fórmula, conforme metodologia utilizada por COELHO DA SILVA (1979); MAYNARD et al. (1984):

$$
\mathrm{CD}=\frac{(\text { Kgcons } \times \% \text { cons })-(\mathrm{kgsb} \times \% \mathrm{sb})-(\mathrm{kgfz} \times \% \mathrm{fz}}{(\text { Kgcons } \times \% \text { cons })-(\mathrm{kgsb}-\% \mathrm{sb})} \times 100
$$

Os valores de todas as variáveis foram analisados por regressão e por comparação de média, segundo o teste de Tukey, utilizando-se o Software Statistical Analysis System (SAS).

\section{RESULTADOS E DISCUSSÃO}

O consumo de matéria seca e dos demais nutrientes pelas ovelhas alimentadas com as dietas com diferentes níveis de FDNf pode ser observado na Tabela 3. 
Tabela 3. Valores médios do consumo de nutrientes das dietas experimentais

\begin{tabular}{lccccc}
\hline \multirow{2}{*}{ Consumo $^{1}$} & \multicolumn{5}{c}{ Dieta com níveis de FNDf } \\
\cline { 2 - 6 } & $8,67 \%$ & $17,34 \%$ & $26,01 \%$ & $34,69 \%$ & CV\% \\
\hline Matéria seca $^{2}$ & $1198,07 \mathrm{~b}$ & $1380,02 \mathrm{a}$ & $1389,04 \mathrm{a}$ & $1448,04 \mathrm{a}$ & 10,88 \\
Matéria orgânica $^{2}$ & $1146,25 \mathrm{~b}$ & $1318,46 \mathrm{a}$ & $1382,65 \mathrm{a}$ & $1324,70 \mathrm{a}$ & 10,91 \\
Fibra em detergente neutro $^{2}$ & $351,03 \mathrm{c}$ & $488,00 \mathrm{~b}$ & $541,17 \mathrm{ab}$ & $604,47 \mathrm{a}$ & 13,63 \\
Fibra em detergente ácido $^{2}$ & $134,77 \mathrm{c}$ & $212,45 \mathrm{~b}$ & $529,74 \mathrm{a}$ & $553,07 \mathrm{a}$ & 7,17 \\
Proteína bruta $^{2}$ & $232,33 \mathrm{~b}$ & $288,14 \mathrm{a}$ & $316,5 \mathrm{a}$ & $313,05 \mathrm{a}$ & 10,58 \\
Proteína digestível $^{2}$ & $173,237 \mathrm{c}$ & $216,60 \mathrm{~b}$ & $242,25 \mathrm{a}$ & $242,12 \mathrm{ab}$ & 12,00 \\
Energia bruta $^{3}$ & $5116,5 \mathrm{~b}$ & $6084,5 \mathrm{a}$ & $6447,2 \mathrm{a}$ & $6062,0 \mathrm{a}$ & 11,40 \\
Energia digestível $^{3}$ & $3962,4 \mathrm{~b}$ & $4522,3 \mathrm{ab}$ & $4764,3 \mathrm{a}$ & $4363,0 \mathrm{ab}$ & 13,88 \\
Energia metabolizável $^{3}$ & $3554,1 \mathrm{~b}$ & $4084,9 \mathrm{ab}$ & $4279,7 \mathrm{a}$ & $3916,1 \mathrm{ab}$ & 13,89 \\
\hline
\end{tabular}

1 - Médias seguidas pela mesma letra, na linha, não diferem entre si pelo teste de Tukey (P>0,05), 2 - g/ovelha/ dia, 3- kcal/ovelha/ dia.

Os consumos de FDN e FDA aumentaram significativamente com o acréscimo de FDNf na dieta. A variação no consumo de FDN foi de 0,68 a $1,34 \%$, enquanto o de FDA foi de 0,29 a $1,22 \%$ em relação ao peso vivo das ovelhas consumindo as dietas com $8,67 \%$ e $34,69 \%$ de FDNf. A maior variação no consumo de FDA, provavelmente, foi devido à seleção dos ingredientes das rações realizada pelos animais, que foi diferente entre os tratamentos, uma vez que a quantidade de volumoso foi crescente entre os tratamentos. Nos tratamentos com menor proporção de volumoso, houve consumo quase total e, às vezes, completo do feno, enquanto que nos demais tratamentos houve consumo parcial e as sobras continham maior proporção de talos, consequentemente, maior quantidade de FDA. Isso foi devido aos ovinos apresentarem alta capacidade de selecionar alimentos (VAN SOEST, 1994).

MACEDO JUNIOR et al. (2009) verificaram que o CFDN e CFDA apresentaram crescimento linear com o aumento dos níveis de FDNf na dieta. O consumo de FDN foi de $34,4 \mathrm{~g} / \mathrm{PV}^{0,75}$ e de $22,4 \mathrm{~g} / \mathrm{PV}^{0,75}$ nas dietas com $35 \%$ e $9 \%$ FDNf. SILVA SOBRINHO et al. (2002), ao trabalharem com diferentes níveis de concentrado na dieta de ovelhas lanadas e deslanadas, observaram que, nos animais que consumiram a dieta com $60 \%$ de concentrado, o consumo de FDN foi similar, com valores de $35,5 \mathrm{~g} / \mathrm{PV}^{0,75}$. No presente estudo, o consumo de FDN foi de $33,35 \mathrm{~g} / \mathrm{PV}^{0,75}$, na dieta com $34,69 \%$ de FDNf, correspondente a $40 \%$ de volumoso. VAN SOEST (1994) cita que vacas leiteiras devam consumir no mínimo $27 \%$ de volumoso na dieta para o bom funcionamento do rúmen. Ainda segundo esse autor, há uma alta correlação entre consumo de MS e teor de FDN na dieta, evidenciando que, quando se aumenta o nível de FDN, reduz-se o consumo de MS. Entretanto, no presente estudo, essa relação ocorreu de forma inversa, isto é, o consumo de MS elevou-se de acordo com o aumento dos níveis de volumoso total utilizados nas dietas experimentais. Esse resultado pode ser explicado por uma melhor condição ruminal com a elevação do volumoso na dieta. VAN SOEST (1994) cita que a fibra é importante fator para o equilíbrio da microbiota ruminal, o que favorece não só o consumo como a digestibilidade da dieta. No entanto, caso os níveis de fibra da dieta cheguem a comprometer o fornecimento de carboidratos fermentáveis de origem não fibrosa, poderia ocorrer redução o consumo de MS (FORBES, 2007).

As análises de regressão do CMS em função dos crescentes níveis de FDNf nas dietas, que estão apresentadas na Tabela 4, demonstraram efeito positivo sobre o CMS, CMO, CFDN, CFDA, CEB e CPB. O consumo de FDNf, em $\mathrm{g} / \mathrm{kgPV}^{0,75}$ apresentou-se de forma linear (Y: 15,6277 + $0,5242 X ; R^{2}=96,30$ ), o que impede concluir que houve uma limitação física do rúmen na regulação do consumo, indicando que este foi, possivelmente, regulado pelo nível energético da dieta (controle fisiológico). O CMS pode ser limitado pelo nível energético da dieta assim como pela quantidade de fibra (volumoso) na dieta, especialmente quando o volumoso for de qualidade inferior. BENEVIDES et al. (2007) observaram que o capim Tanzânia não deve ser pastejado por ovinos por um período superior ao tempo necessário para emissão de 2,5 novas folhas por perfilho. Segundo MACEDO JUNIOR et al. (2006), existe um limite mínimo 
fisiológico de inclusão de forragem na dieta de ruminantes. Observa-se na Tabela 3 que dietas com menos de $20 \%$ de FDNf apresentam redução no consumo de matéria seca. $\mathrm{O}$ mesmo comportamento foi observado em vários trabalhos (ALVES et al.,
2000; FURUSHO GARCIA et al., 2003; BURGER et al., 2006; CARVALHO et al., 2006; DADO \& ALLEN 2006; MACEDO JUNIOR et al., 2006; e MACEDO JUNIOR et al., 2007).

Tabela 4. Equações de regressão ajustadas para consumo de nutrientes em função dos níveis de FDNf (X) e respectivos coeficientes de variação $(\mathrm{CV})$ nas diferentes dietas

\begin{tabular}{lccc}
\hline \multicolumn{1}{c}{ Consumo } & Equações de regressão ${ }^{1}$ & $\mathrm{R}^{2}(\%)$ & $\mathrm{CV}(\%)$ \\
\hline Matéria seca $^{2}$ & $\mathrm{Y}: 892,7762+42,0727 \mathrm{X}-0,7996 \mathrm{X}^{2}$ & 99,98 & 10,88 \\
Matéria orgânica $^{2}$ & $\mathrm{Y}: 855,5143+40,0857 \mathrm{X}-0,7651 \mathrm{X}^{2}$ & 99,97 & 10,91 \\
Fibra em detergente neutro $^{2}$ & $\mathrm{Y}: 200,6975+20,0058 \mathrm{X}-0,2451 \mathrm{X}^{2}$ & 98,74 & 13,63 \\
Fibra em detergente ácido $^{2}$ & $\mathrm{Y}: 4,4696+0,0516 \mathrm{X}$ & 93,84 & 7,17 \\
Proteína bruta $^{2}$ & $\mathrm{Y}: 145,6084+11,6977 \mathrm{X}-0,1979 \mathrm{X}^{2}$ & 94,06 & 10,58 \\
Proteína digestível $^{2}$ & $\mathrm{Y}: 145,6084+11,6977 \mathrm{X}-0,1979 \mathrm{X}^{2}$ & 99,99 & 12,00 \\
Energia bruta $^{3}$ & $\mathrm{Y}: 3437,0118+231,8890 \mathrm{X}-0,4973 \mathrm{X}^{2}$ & 99,90 & 11,40 \\
Energia digestível $^{3}$ & $\mathrm{Y}: 2841,0546+155,1643 \mathrm{X}-3,1946 \mathrm{X}^{2}$ & 98,45 & 13,88 \\
Energia metabolizável $^{3}$ & $\mathrm{Y}: 2520,9576+143,6548 \mathrm{X}-2,9725 \mathrm{X}^{2}$ & 99,19 & 13,89 \\
\hline
\end{tabular}

1 - Significativo a $5 \%$ de probabilidade, 2 - g/ovelha/ dia, 3- kcal/ovelha/ dia.

VAN SOEST (1994) cita que há redução no consumo de MS quando se utiliza grande quantidade de carboidratos solúveis ou amido nas dietas conforme citado por SILVEIRA (2002). O NRC (1985) sugere que em dietas que possuam mais de $70 \%$ de concentrado, o consumo de forragens é insuficiente para que a fermentação ruminal mantenha-se nos parâmetros fisiológicos. Neste ensaio, níveis crescentes de 60 a $90 \%$ de concentrado na dieta apresentam efeito positivo sobre parâmetros fisiológicos (digestibilidade e balanço de N) e sobre um parâmetro altamente correlacionado com a produção animal (consumo de MS).

As ovelhas deste estudo apresentaram consumo médio de matéria seca de 1007,94 $\mathrm{g} / \mathrm{animal} / \mathrm{dia}$ ou 2,2\% PV, mostrando que o consumo de matéria seca esteve próximo ao recomendado pelo NRC (1985), ou seja, que o consumo de MS deve ser de $1 \mathrm{~kg}$ ou 2,0 \% do peso vivo. Mesmo sofrendo influência negativa dos carboidratos solúveis ao longo do período experimental, verificaram-se variações aleatórias no CMS, que sugeriam um quadro de acidose ruminal sub-clínica; entretanto, não houve casos clínicos comprovados.
O consumo de energia e proteína bruta reduziram (Tabela 3) com o decréscimo de FDNf nas dietas experimentais, possivelmente, influenciados pelo menor consumo de MS nesses tratamentos. Conforme os níveis de FDNf se elevaram, houve efeito quadrático no CED e CEM (Tabela 4). Contudo, observa-se que o tratamento com menor quantidade de FDNf $(8,67 \%)$ teve o menor consumo de energia digestível e metabolizável. O NRC (1985) recomenda que para ovelhas adultas em mantença, com $50 \mathrm{~kg}$ de peso vivo, o CED seja de $2400 \mathrm{kcal}$ e o CEM seja de $2000 \mathrm{kcal}$ por dia. Os menores CED e CEM deste estudo foram de 3962,4 kcal/animal/dia e 3554,1 $\mathrm{kcal} / \mathrm{animal} / \mathrm{dia}$, respectivamente, mostrando que, mesmo os menores consumos aqui obtidos, foram superiores às recomendações do NRC (1985). Mais uma vez torna-se claro que houve efeito negativo da alta quantidade de carboidratos solúveis no equilíbrio ruminal.

Os coeficientes médios de digestibilidade aparente da matéria seca (DMS), matéria orgânica (DMO), energia bruta (DEB), proteína bruta (DPB), fibra em detergente neutro (DFDN) e fibra em detergente ácido (DFDA) podem ser observados na Tabela 5. 
Tabela 5. Coeficientes médios de digestibilidade aparente dos nutrientes das dietas contendo diferentes concentrações de fibra em detergente neutro de origem forrageira

\begin{tabular}{lccccc}
\hline \multicolumn{1}{c}{ Coeficientes } & \multicolumn{5}{c}{ Dieta com níveis de FNDf } \\
\cline { 2 - 6 } de digestibilidade $(\%)$ & $8,67 \%$ & $17,34 \%$ & $26,01 \%$ & $34,69 \%$ & $\mathrm{CV}(\%)$ \\
\hline Matéria seca & $78,13 \mathrm{a}$ & $74,24 \mathrm{ab}$ & $73,62 \mathrm{~b}$ & $71,95 \mathrm{~b}$ & 5,65 \\
Matéria orgânica & $79,34 \mathrm{a}$ & $75,87 \mathrm{ab}$ & $75,14 \mathrm{~b}$ & $73,48 \mathrm{~b}$ & 5,23 \\
Energia bruta & $77,12 \mathrm{a}$ & $74,06 \mathrm{ab}$ & $73,87 \mathrm{ab}$ & $72,06 \mathrm{~b}$ & 5,77 \\
Proteína bruta & $74,73 \mathrm{a}$ & $74,95 \mathrm{a}$ & $76,58 \mathrm{a}$ & $77,17 \mathrm{a}$ & 6,38 \\
Fibra em detergente neutro & $57,42 \mathrm{a}$ & $55,78 \mathrm{a}$ & $55,69 \mathrm{a}$ & $59,13 \mathrm{a}$ & 14,80 \\
\hline
\end{tabular}

Médias seguidas pela mesma letra, na mesma linha não diferem pelo teste de Tukey $(\mathrm{P}>0,05)$.

Quando o consumo do MS elevou-se, houve redução na digestibilidade das dietas, provavelmente, em função do aumento de FDNf, aumentando, então, a quantidade de carboidrato estrutural e, consequentemente, piorando a qualidade da mesma, pois tais carboidratos apresentam menor digestibilidade que aqueles não estruturais. VALADARES FILHO (1985) cita que carboidratos solúveis apresentam digestibilidade próxima a $90 \%$ e carboidratos estruturais de aproximadamente $50 \%$. Assim, o aumento de fibra na dieta pode ter causado a redução da DMS. BERCHIELLI et al. (2006) afirmaram que a qualidade do volumoso, a forma de apresentação e a quantidade de carboidratos solúveis podem interferir na DMS.

$A$ digestibilidade da $P B$ não foi influenciada pelos níveis de FDNf das dietas experimentais, provavelmente, devido a problemas que afetaram o consumo de MS e que podem ter afetado a relação entre a energia e proteína.

As equações de regressão dos DMS, DMO, DEB, DPB, DFDN, em função dos níveis de FDNf, encontram-se na Tabela 6. As equações de regressão para o DMS e DMO apresentaram-se de forma linear, aumentando de acordo com o decréscimo no nível de FDNf das dietas experimentais.

Tabela 6. Equações de regressão de coeficientes da digestibilidade aparente dos nutrientes e balanço de nitrogênio em função dos níveis de FDNf da dieta (X)

\begin{tabular}{lccc}
\hline \multicolumn{1}{c}{$\begin{array}{c}\text { Coeficientes } \\
\text { de digestibilidade (\%) }\end{array}$} & Equações de regressão $^{1}$ & CV (\%) & $\mathrm{R}^{2}(\%)$ \\
\hline Matéria seca & Y: $0,7925-0,0022 \mathrm{X}$ & 5,65 & $89,00^{1}$ \\
Matéria orgânica & $\mathrm{Y}: 0,8054-0,0021 \mathrm{X}$ & 5,23 & $91,86^{1}$ \\
Energia bruta & Y: 0,7830-0,0018X & 5,77 & $90,94^{1}$ \\
Proteína bruta & Y: NS & 6,38 & \\
Fibra em detergente neutro & Y: NS & 14,80 & \\
N ingerido (g/ovelha/ dia) & Y: 23,2976 + 1,8716X - 0,0316X & 10,58 & $99,99^{1}$ \\
N fecal (g/ovelha/ dia) & Y: NS & 24,34 & \\
N urinário (g/ovelha/ dia) & Y:NS & 22,46 & \\
N retido (g/ovelha/ dia) & Y: 8,4125 + 1,1625X - 0,0168X & 19,53 & $99,90^{1}$ \\
\hline 1 - Significativo a 5\% de probabilidade, NS - Não significativo. & & &
\end{tabular}

A DEB apresentou-se de forma linear, declinando à medida que se elevaram os teores de FDNf nas dietas. Fica claro que a DEB foi determinada pela digetibilidade da MS e MO, as quais tiveram respostas muito similares entre si. Sendo assim, credita-se que tais observações deveram-se ao aumento de FDNf nas dietas, uma vez que esse nutriente possui o menor coeficiente de 
digestibilidade dentre os demais. Os tratamentos não influenciaram a DFDN, corroborando com BOLZAN et al. (2002) que também não o observaram quando aumentaram as quantidades de concentrado nas dietas.

$\mathrm{Na}$ Tabela 7 estão apresentados os valores médios de nitrogênio $(\mathrm{N})$ ingerido, $\mathrm{N}$ fecal, $\mathrm{N}$ urinário, $\mathrm{N}$ retido, sobre o nitrogênio retido (\% sobre o ingerido) em ovelhas alimentadas com diferentes concentrações de fibra em detergente neutro de origem forrageira nas dietas e na Tabela 6 estão apresentadas as equações de regressão do $\mathrm{N}$ retido, $\mathrm{N}$ fecal, $\mathrm{N}$ urinário e $\mathrm{N}$ ingerido, em função dos níveis de FDNf das dietas.

Tabela 7. Valores médios diários do balanço de nitrogênio em ovelhas alimentadas com diferentes concentrações de fibra em detergente neutro de origem forrageira nas dietas

\begin{tabular}{llllll}
\hline \multirow{2}{*}{ VARIÁVEL } & \multicolumn{5}{c}{ Dieta com níveis de FNDf } \\
\cline { 2 - 6 } & $8,67 \%$ & $17,34 \%$ & $26,01 \%$ & $34,69 \%$ & $\mathrm{CV}(\%)$ \\
\hline $\mathrm{N}$ ingerido (g/ animal) & $37,17 \mathrm{~b}$ & $46,15 \mathrm{a}$ & $50,64 \mathrm{a}$ & $50,09 \mathrm{a}$ & 10,58 \\
$\mathrm{~N}$ fecal (g/ animal) & $9,46 \mathrm{a}$ & $11,49 \mathrm{a}$ & $11,88 \mathrm{a}$ & $11,35 \mathrm{a}$ & 24,34 \\
$\mathrm{~N}$ urinário (g/ animal) & $10,43 \mathrm{a}$ & $11,33 \mathrm{a}$ & $11,31 \mathrm{a}$ & $10,31 \mathrm{a}$ & 22,46 \\
$\mathrm{~N}$ retido (g/ animal) & $17,29 \mathrm{c}$ & $23,32 \mathrm{~b}$ & $27,45 \mathrm{ab}$ & $28,43 \mathrm{a}$ & 19,53 \\
\hline
\end{tabular}

Médias seguidas pela mesma letra, na mesma linha não diferem pelo teste de Tukey $(\mathrm{P}>0,05)$

Verificou-se que o consumo de $\mathrm{N}$ foi menor no tratamento com menor nível de FDN. Como as dietas foram formuladas para serem isoprotéicas, a redução verificada no consumo de MS desse tratamento pode ser considerada como a principal responsável pela redução no consumo nitrogenado.

Não foi observada influência dos níveis de FDNf no $\mathrm{N}$ (g/ovelha/ dia) perdido nas fezes e na urina. Os animais, consumindo as dietas com menores níveis de FDNf, de 8,67 e 17,34\%, tiveram a menor quantidade de $\mathrm{N}$ retido. Isso pode ser explicado pelo fato de que esses tratamentos tiveram menores consumos de $\mathrm{N}$, em função da redução do consumo de MS, PD e EM, promovendo, assim, menor retenção de $\mathrm{N}$, uma vez que a relação proteína:energia pode ter afetado de modo significativo a retenção de nitrogênio. Possivelmente, o excesso de carboidratos de rápida fermentação afetou o desenvolvimento das bactérias, reduzindo a retenção de $\mathrm{N}$, pois, quando se elevou a quantidade de FDNf, observaram-se maiores quantidades de $\mathrm{N}$ retido, sugerindo interferência dos baixos níveis de FDNf que promoveram uma queda no CMS dos tratamentos com menores níveis de FDNf e, com isso, teriam influenciado também a retenção de $\mathrm{N}$.

Outro possível fator é o deslocamento do sítio de digestão para o intestino grosso (IG). FURLAN et al. (2006) afirmaram que a digestibilidade do milho no IG é menor. No presente estudo, o concentrado continha milho e soja moídos em sua composição. A absorção de $\mathrm{N}$ no IG é baixa uma vez que a microbiota formada nesse órgão é perdida nas fezes. Comparando os resultados de $\mathrm{N}$ fecal e $\mathrm{N}$ urinário deste estudo com os valores de $\mathrm{N}$ fecal encontrados por PIRES et al. (2008), que foram de 7,63 g/dia e 8,57 g/dia para ovelhas com um e dois fetos, respectivamente, e, para $\mathrm{N}$ urinário, de $4,99 \mathrm{~g} / \mathrm{dia}$ e $5,31 \mathrm{~g} / \mathrm{dia}$ para ovelhas com um e dois fetos, respectivamente, verifica-se que a quantidade de $\mathrm{N}$ observada neste trabalho é numericamente superior, evidenciando altas perdas de $\mathrm{N}$ na urina e nas fezes. $\mathrm{O}$ valor médio de $\mathrm{N}$ retido em relação ao consumido foi de $51,10 \%$, superior ao valor de $26,32 \%$ verificado por ROCHA (2002), trabalhando com ovinos Santa Inês.

\section{CONCLUSÃO}

Existem evidências de um limite fisiológico para utilização de concentrado na dieta de ovinos, sendo necessário um mínimo de FDNf para maior eficiência no aproveitamento dos nutrientes.

\section{REFERÊNCIAS}

ALLISON, C.D.. Factors affecting forage intake by ruminants: a review. Journal Range Managment. 38(4):305-311. 1985

ALVES, K.S.; CARVALHO, F.F.R.; VERAS, A.S.C. Níveis de energia em dietas para ovinos Santa Inês. Revista Brasileira de Zootecnia, v.32, n.6, p.1962-1968, 
2003. Supl.2.

AGRICULTURAL RESEARCH COUNCIL. The nutrient requirement of farm animals. London, 1980. $351 \mathrm{p}$.

BENEVIDES, Y. I.; M., CÂNDIDO, J. D.; NEIVA, J. N. M.; BORGES, I.; SILVA, A. G. M.; SILVA, R.G. da. Composição e degradabilidade da dieta de ovinos em capim Tanzânia com três períodos de descanso. Archivos de Zootecnia, v. 56, n. 214, p. 215-226. 2007.

BÜRGER, P.J.; PEREIRA, J.C.; QUEIROZ, A.C. Comportamento ingestivo em bezerros holandeses alimentados com dietas contendo diferentes níveis de concentrado. Revista Brasileira de Zootecnia. v.29, p.236-242, 2000.

CARVALHO, S.; RODRIGUES, M.T.; BRANCO, R.H. Comportamento ingestivo de cabras alpinas em lactação alimentadas com dietas contendo diferentes níveis de fibra em detergente neutro proveniente de forragem. Revista Brasileira de Zootecnia, v.35, p.562-568, 2006.

COELHO DA SILVA, J. F.; LEÃO, M. I. Fundamentos da nutrição dos ruminantes. Piracicaba: Livro Ceres, 1979. 380p.

DADO, R.G.; ALLEN, M.S. Intake limitation, feeding behavior and rumen function of cows challenged with rumen fill from dietary fiber or inert bulk. Journal of Dairy Science. v.78, p.118-133, 1995.

FORBES, J. M. Voluntary food intake and diet selection in farm animals. Wallingford: $C A B$ International, 1995. 532p.

FURUSHO-GARCIA, I.F.; PEREZ, J.R.O.; OLIVEIRA, M.V.M. Componentes corporais e órgãos internos de cordeiros Texel x Bergamácia, Texel x Santa Inês e Santa Inês puros, terminados em confinamento, com casca de café como parte da dieta. Revista Brasileira de Zootecnia, v.32, n.6, p.1992-1998, 2003. Supl.2.

MACEDO JÚNIOR, G.L.; PEREZ, J.R.O.; PAULA, O.J.; ALMEIDA, T.R.V.; ASSIS, R.M.; FRANÇA, P.M. Influência de diferentes níveis de FDN dietético no consumo e digestibilidade aparente de ovelhas Santa Inês. Ciência e Agrotecnologia, v.30, n.3 p.547-553, 2006.

MACEDO JÚNIOR, G.L.; PEREZ, J.R.O.; ZANINE, A.M.; BORGES, I.; PÉREZ, J.R.O. Qualidade da fibra para a dieta de ruminantes. Ciência Animal, v.17, n.1, p.7-17, 2007.

MACEDO JUNIOR, G. L.; FRANÇA, P. M.; ASSIS, R. M.; ALMEIDA, T. R. V.; PAULA, O. J.; PÉREZ, J. R. O.; BAIÃO, A. A. F.; BORGES, I.; SILVA, V. B. Níveis de fibra em detergente neutro forrageiro na alimentação de ovelhas Santa Inês gestantes. Arquivo Brasileiro de Medicina Veterinária e Zootecnia. v. 61, n. 1, p. 196202, 2009.

MAYNARD, L. A.; LOOSLI, B. S.; HINTZ, H. F.; WARNER, R. G. Nutrição animal. 3. ed. Rio de Janeiro: Freitas Bastos, 1984. 726p.

NATIONAL RESEARCH COUNCIL. Nutrient requirements of sheep. 6.ed. Washington: National Academy, 1985. 99p.

ROCHA, M. H. M. Teores de proteína bruta em dietas com alta proporção de concentrado para cordeiros confinados. Dissertação (Mestrado em Zootecnia)-Escola Superior de Agricultura "Luis de Queiroz", Piracicaba, SP. 2002. http://www.teses.usp.br/teses/disponiveis/11/11139/t de-08082002-154534/pt-br.php

SILVA SOBRINHO, A.G. SILVA, A. M. A.; TRINDADE, I. A. C. M.; RESENDE, K. T. VIEIRA, E. L.Efeitos da relação Volumoso:Concentrado e do peso ao abate sobre os componentes da perna de cordeiros Ile de France $x$ Ideal confinados. Revista Brasileira de Zootecnia. v.31, p.1017-1023, 2002.

SILVA, D. J. e QUEIROZ, A.C. Análise de alimentos (métodos químicos e biológicos). 3. ed. Viçosa: UFV, 2002, 166p.

SILVEIRA, A. L. F. Avaliação nutricional da adição de uréia a dieta baseada em feno de média qualidade suplementada com milho moído. 2002. 124f. Dissertação (Mestrado em Zootecnia)-Universidade Federal do Rio Grande do Sul, Porto Alegre. Disponível em http://hdl.handle.net/10183/1605

SNIFFEN, C. J.; O'CONNOR, J. D.; VAN SOEST, P. S. A net carbohydrate and protein availability. Journal Animal Science., v. 70, n, 3, p. 3562-3577, 1992.

VAN SOEST, P. J. Nutritional ecology of the ruminants. Corvallis: O e Books, 1982. 373p.

VAN SOEST, P. J. Nutritional ecology of the ruminants. 2.ed. Ithaca: Cornell University, 1994. 476p. 